\title{
Characteristics of Plasmacytoid Dendritic Cell and CD4+ T Cell in HIV Elite Controllers
}

\author{
Jean-Philippe Herbeuval, ${ }^{1}$ Nikaiia Smith, ${ }^{2}$ and Jacques Thèze ${ }^{3}$ \\ ${ }^{1}$ CNRS UMR 8147 and Hôpital Necker, Université Paris Descartes, 149-161 rue de Sèvres, \\ 75015 Paris, France \\ ${ }^{2}$ CNRS UMR 8601, Université Paris Descartes, 45 rue des Saint-Pères, 75006 Paris, France \\ ${ }^{3}$ Unité d'Immunologie Humaine, Centre Medical Necker Pasteur, Institut Pasteur, 28 Rue du Docteur Roux, \\ 75015 Paris, France
}

Correspondence should be addressed to Jean-Philippe Herbeuval, jean-philippe.herbeuval@parisdescartes.fr

Received 21 August 2012; Revised 22 October 2012; Accepted 23 October 2012

Academic Editor: Vicki L. Traina-Dorge

Copyright ( 92012 Jean-Philippe Herbeuval et al. This is an open access article distributed under the Creative Commons Attribution License, which permits unrestricted use, distribution, and reproduction in any medium, provided the original work is properly cited.

\begin{abstract}
Despite variability, the majority of HIV-1-infected individuals progress to AIDS characterized by high viral load and massive CD4+ T-cell depletion. However, there is a subset of HIV-1-positive individuals that does not progress and spontaneously maintains an undetectable viral load. This infrequent patient population is defined as HIV-1 controllers (HIV controllers), and represents less than $1 \%$ of HIV-1-infected patients. HIV-1-specific CD4+ T cells and the pool of central memory CD4+ T cells are also preserved despite immune activation due to HIV-1 infection. The majority of HIV controllers are also defined by the absence of massive CD4+ T-cell depletion, even after 10 years of infection. However, the mechanisms involved in protection against HIV-1 disease progression have not been elucidated yet. Controllers represent a heterogeneous population; we describe in this paper some common characteristics concerning innate immune response and CD4+ T cells of HIV controllers.
\end{abstract}

\section{Plasmacytoid Dendritic Cells}

The innate immune system is our first line of defense against invading microorganisms while the adaptive immune system acts as a second line of defense and also affords protection against reexposure to the same pathogen. One of the hallmarks of the innate immune response is the production of the antiviral cytokine type I IFN (IFN- $\alpha$ and $\beta$ ): these factors inhibit viral replication and spreading [1]. Plasmacytoid dendritic cells (pDC) are the most potent IFN$\alpha$-producing cells $[2,3]$ and serve as an essential link between innate and adaptive immunity [4].

PDC are cells of hemopoietic origin that are found at steady state in the blood, thymus, and peripheral lymphoid tissues [5]. Early studies described pDCs as being oval shaped with typical plasmacytoid morphology. The ability of plasmacytoid-derived DCs (also named DC2) to induce a Th2 differentiation of naïve CD4+ T cells formed the basis for the concept of type 1 and type 2 DC [5]. The role of these
DC in mouse and human was studied in different models and is not completely elucidated [6]. A little later, it was shown that $\mathrm{pDC}$ were specialized in the production of type I IFN [2]. They are the principal source of type I IFN in human blood and very rapidly produce all type I IFN isoforms in response to microbial stimuli, such as virus $[2,7]$, CpGcontaining oligonucleotides [8], or the synthetic molecules imidazoquinolines [9]. PDC-derived type I IFN has direct antiviral activity against a variety of viruses, including HIV, and has important adjuvant functions on other immune cell types, such as NK cells, T cells, macrophages and DC [10, 11]. Thus, pDC activation triggers a dual type of response: type I IFN production and DC differentiation $[5,12]$.

PDCs express the Toll-like receptors TLR7 and TLR9 $[13,14]$ and respond to their respective ligands, imidazoquinolines [15] and single-strand RNA [16-18] for TLR7, CpG-containing oligonucleotides [19] and DNA viruses [20] for TLR9. They do not express TLR2, TLR3, and TLR4 
and do not respond to such ligands as peptidoglycan, LPS (lipopolysaccharides), or double-stranded RNA [13, 14]. Activation of pDC through TLR7 and TLR9 can trigger both types of response, including large quantities of type I IFN production and/or DC differentiation [6]. Synthetic CpGcontaining oligonucleotides of the types $\mathrm{A}$ and $\mathrm{B}$ (CpG-A, CpG-B) selectively induce type I IFN production and DC differentiation, respectively [21], while some viral stimuli, such as influenza virus (Flu), herpes simplex virus (HSV), or CpG-C can induce simultaneously both responses [6]. Two factors seem to be keys for the induction of large quantities of type I IFN in pDC: (1) the ability of the TLR ligands to bind its receptor in the early endosomal compartments [22, 23]; (2) the phosphorylation and nuclear translocation of the transcription factor IRF-7 [24]. This last step was shown to depend on the kinases IRAK-1 [25] and IkB kinase-a (IKK-a) [26] in mouse pDC. It has been recently shown that the PI3-kinase pathway was critical to control the nuclear translocation of IRF-7 and the subsequent production of type I IFN [27].

PDCs express a panel of surface receptors but pDC's function remains largely unknown. The best characterized is the lectin BDCA-2 (blood dendritic cell antigen-2) [28, 29]. Neuropilin 1 (NRP1), also called BDCA-4, is another surface receptor constitutively expressed at high levels on human pDC. NRP1 is involved in the interaction between myeloid DC and T cells within the immune synapse [30].

PDCs are involved in several disease settings; however, their precise role remains to be elucidated. They were observed in situ in a variety of pathological conditions, such as HPV-related cervical cancer, skin melanoma [31], psoriasis [32], or allergic contact dermatitis [33] and in the nasal mucosa as early as 6 hours after allergen challenge, suggesting an active recruitment of blood $\mathrm{pDC}$ at the site of inflammation. Moreover, a dysregulated TLR-induced IFN response has been linked to autoimmune diseases $[34,35]$, particularly lupus erythematous and psoriasis [32].

\section{2. $\mathrm{pDC}$ in HIV-1 Infection}

The role of pDC in HIV-1 infection is not well understood and is still debating. It may be radically different depending on the stage of the disease. The first studies reported that the number of circulating pDC was decreased in HIV-1 infection [36], and that the lack of IFN- $\alpha$ production was suggested to be responsible for HIV-1 disease progression $[37,38]$. Furthermore, pDC from HIV-1-infected patients seemed to be functionally deficient as they produced less IFN- $\alpha$ in response to viral infection compared to pDC from healthy donors $[39,40]$. However, recent studies highlighted a more complex role of IFN- $\alpha$ and pDC activation/death during the different stages of the disease than previously thought. It has been suggested that virus control is required to keep the balance between $\mathrm{pDC}$ response and pDC depletion [41].

The decreased number of $\mathrm{pDC}$ in blood could have two major causes: either pDCs undergos apoptosis due to infection by HIV-1, HIV-1 pathogenesis, and/or generalized immune dysregulation or pDCs migrate to secondary lymph tissues and potentially could die [42].

The first cause of pDC blood depletion could be due to the infection by HIV-1. Some arguments are in favor of this theory, as pDCs express the principal receptor for HIV-1 (CD4), but also the two coreceptors (CXCR4 and CCR5) [2]. Furthermore, it has been shown that a significant proportion of pDC was infected by SIV in a simian model [43] and that the maturation marker CD40 ligand was necessary for virus replication, which could alter pDC viability $[1,44]$. Although pDCs are susceptible to HIV-1 infection and as a result may die, this is unlikely the only cause responsible for pDC depletion in humans. Indeed, approximately $1 \%$ of blood pDC from HIV-1 patients contained proviral DNA [45] and pDCs are not a major reservoir for HIV-1 in vivo [46]. Furthermore, we showed that infectious HIV-1, but also chemically inactivated HIV-1 (AT-2 HIV-1), had no cytotoxic effect on pDC. Actually those stimuli induced metabolic activation rather than apoptosis, due to the fact that IFN- $\alpha$ secretion provides strong antiapoptotic signals in pDC $[47,48]$.

The second cause of pDC depletion could be explained by migration of pDCs in lymph nodes and spleen, phenomenon that could also induce early cell death. It is likely that the second hypothesis occurs in vivo, with a redistribution of HIV-1-activated pDC in lymphoid organs [49]. Indeed, pDCs were found to be positive for p24 in tonsils of HIV-1-infected patients $[44,50]$, demonstrating an in vivo proof for $\mathrm{pDC}$ migration $[51,52]$. Several studies, including ours, reported that in vitro HIV-1 activation of pDC resulted in cytokine production but also activation markers (CD40, HLADR), maturation markers (CD80, CD86), and migration marker CCR7 [51, 53-55]. CCR7 induces a cell migration to lymphoid organs when stimulated by its natural ligand (CCL19, CCL21). It should be noted that both infectious and noninfectious HIV-1 stimulated CCR7 expression and IFN- $\alpha$ production by pDC [56]. Furthermore, pDCs isolated from the blood of HIV-1-infected patients express CCR7 and also the activation marker HLADR [52]. Thus, CCR7 expression could potentially lead to migration of HIV-1-activated pDC to lymphoid organs [49]. Furthermore, Stary et al. clearly demonstrated that pDC expressed the apoptotic ligand TRAIL in viremic HIV-1infected patients' tonsils [49]. Interestingly, in the spleens of some patients with high proviral loads, pDCs are more numerous than in controls or in spleens from patients with lower viral loads [57]. This strongly suggests a homing of pDC towards spleens in humans as well as in macaques [58].

Finally, the combination of both causes (migration and death) may explain the reduction of pDC number in the blood and lymphoid organs of viremic patients. Indeed, pDCs are lost from blood and lymph nodes two weeks after intravenous infection with HIV despite strong mobilization of pDC to lymph nodes. In lymph nodes, the vast majority of pDC is activated and only a smaller proportion undergoes apoptosis due to hostile inflammatory environment of SIV-infected macaques [59]. Furthermore, 
the same phenomenon of migration and depletion may occur in HIV-infected human lymph nodes [60].

\section{3. pDC and CD4+ T Cells in HIV-Infected Controllers (HIV Controllers)}

As recently suggested [41], virus control is required to keep the balance of $\mathrm{pDC}$ response that will result in the elimination of HIV-infected cells, reduced viral replication, and survival of CD4+ T cells. It is possible that early ART prevents chronic stimulation of the pDCs and allows the preservation of their functions, as a recent study showed that prolonged ART initiated at the time of HIV-1 seroconversion is associated with a polyfunctional immunological T-cell status that is similar to that of LTNPs [61].

Because pDC response may have a major impact for HIV-1 disease progression, studying $\mathrm{pDC}$ in human and simian AIDS resistant models remains essential. There is now a debate in the literature concerning the activation of pDC in AIDS-resistant simian models. One study showed that the resistance to AIDS progression in sooty mangabey model was explained by a deficient IFN- $\alpha$ production by $\mathrm{pDC}$ in response to SIV [62]. In contrast, it was recently shown that pDC could be activated by SIV [43] and produce high levels of type I IFN similarly in AIDS-resistant and AIDS susceptible simian models [63-65]. The kinetic study of acute and chronic SIV infection demonstrated that the difference between pathogenesis resistant African green monkey (AGM) and susceptible Rhesus macaque (RM) resides in the kinetics of interferon-stimulated genes (ISG) expression. Resistance was associated with a peak at around 2 weeks after infection, followed by a decline to near-baseline levels by 4 weeks $[64,65]$. In contrast, RM followed a generally similar kinetics until the decline, with leveled off well above the baseline to become chronic [63].

In humans, the role of $\mathrm{pDC}$ and IFN- $\alpha$ during the different stages of HIV pathogenesis seems to be multifaceted, and it has been recently demonstrated that activated pDC and IFN- $\alpha$ contribute to chronic immune activation and T-cell depletion $[49,66]$. In addition to type I IFN production, we previously showed that HIV transforms pDC into killer pDC (IKpDC) [55]. More precisely, in human tonsils, chronic activation of pDC by HIV particles induced TRAIL expression transforming them into killer cells, which induced apoptosis of CD4+ T cells [49]. Thus, we recently studied pDC response and TRAIL pathway in HIV controllers. We found that pDC from HIV controllers did not exhibit any quantitative or functional deficiencies in membrane TRAIL expression when stimulated by infectious or noninfectious HIV-1 particles. Our results also showed that in vivo most of pDC from HIV controllers did not express TRAIL on their membrane contrasting with the $30 \%$ of TRAIL-expressing pDC from viremic patients [39]. However, pDC from controller patients showed high levels of membrane TRAIL expression after viral stimulation. In addition, microscopy analysis of circulating pDC from viremic patients revealed the existence of TRAIL expressing
IKpDC [39], confirming the in vivo generation of this cell subset during HIV infection [49].

Thus, PDCs from HIV controllers produce IFN- $\alpha$ and express membrane TRAIL after viral stimulation in vitro, transforming them into IKpDC $[39,40]$. The fact that pDCs from HIV controllers do express mTRAIL after stimulation suggests that they are less stimulated in vivo, probably due to the nearly absence of HIV particles in the blood. Thus, pDCs are not activated and probably do not migrate to lymphoid organs, explaining the elevated number of pDC in blood from HIV controllers compared to viremic patients. These results are consistent with our previous study showing that tonsils from controllers do not exhibit IFN- $\alpha$ staining and TRAIL mRNA in contrast to tonsils from viremic [52]. In conclusion, qualitative and functional involvement of pDC is necessary for the spontaneous control of HIV viremia. These findings highlight the important role of innate immunity in HIV immunopathogenesis and could have important immunotherapeutic applications. Furthermore, in accordance to simian models, HIV controller patients maintained elevated pDC blood number. In culture, pDCs from HIV controller produce high levels of IFN- $\alpha$ in response to HIV exposure contrasting with pDC from viremic patients that statistically produced less IFN- $\alpha$ than pDC from HIV controllers (Figure 1 and Table 1).

Finally, we observed that IKpDC could induce apoptosis of CD4+ T cells. This result combined with TRAIL expression and the high levels of IFN- $\alpha$ produced by pDC from HIV controllers after viral stimulation suggest that, in contrast to some simian models, pDCs from controllers are fully functional and do not show any impairment. However, HIV controllers usually keep high CD4+ T-cell counts (Figure 1). Interestingly, we found that CD4+ T cells from HIV controllers did undergo only limited apoptosis when cultured with HIV (personal data). In contrast, in our study, we clearly demonstrated that pDCs from HIV controllers are able to induce apoptosis of DR5 expressing cell line, thus this finding can not be explained by a weak pDC functionality in HIV controllers but by a particularity of $\mathrm{CD} 4+\mathrm{T}$ cells that remained to be investigated.

CD4+ T cells from elite controllers are less susceptible to HIV infection compared to HIV progressors and healthy donors. HIV gene expression is decreased when the known tumor suppressor gene called p21 is upregulated as observed in most of HIV controllers. This potentially leads to the resistance of those controllers.

Multiple mechanisms contribute to CD4+ T-cell depletion in HIV infection (reviewed in [67]). During chronic immune activation, there is an increase programmed cell death (apoptosis) of CD4+ T cell subsets. The decline of the rate of memory $\mathrm{CD} 4+\mathrm{T}$ cells $\left(\mathrm{T}_{\mathrm{CM}}\right.$ cells) is predictive for disease progression. The resistance of those cells to apoptosis correlates with immunological protection in HIV and SIV infections [68]. We then wonder whether CD4+ T cells in HIV controllers have a higher survival rate compared to subjects with progressive disease. A recent study [69] showed that when T-cell receptors are triggered, $\mathrm{T}_{\mathrm{CM}}$ and effector memory CD4+ T cells ( $\mathrm{T}_{\mathrm{EM}}$ cells) from elite controllers are less susceptible to Fas-mediated apoptosis and persist longer 


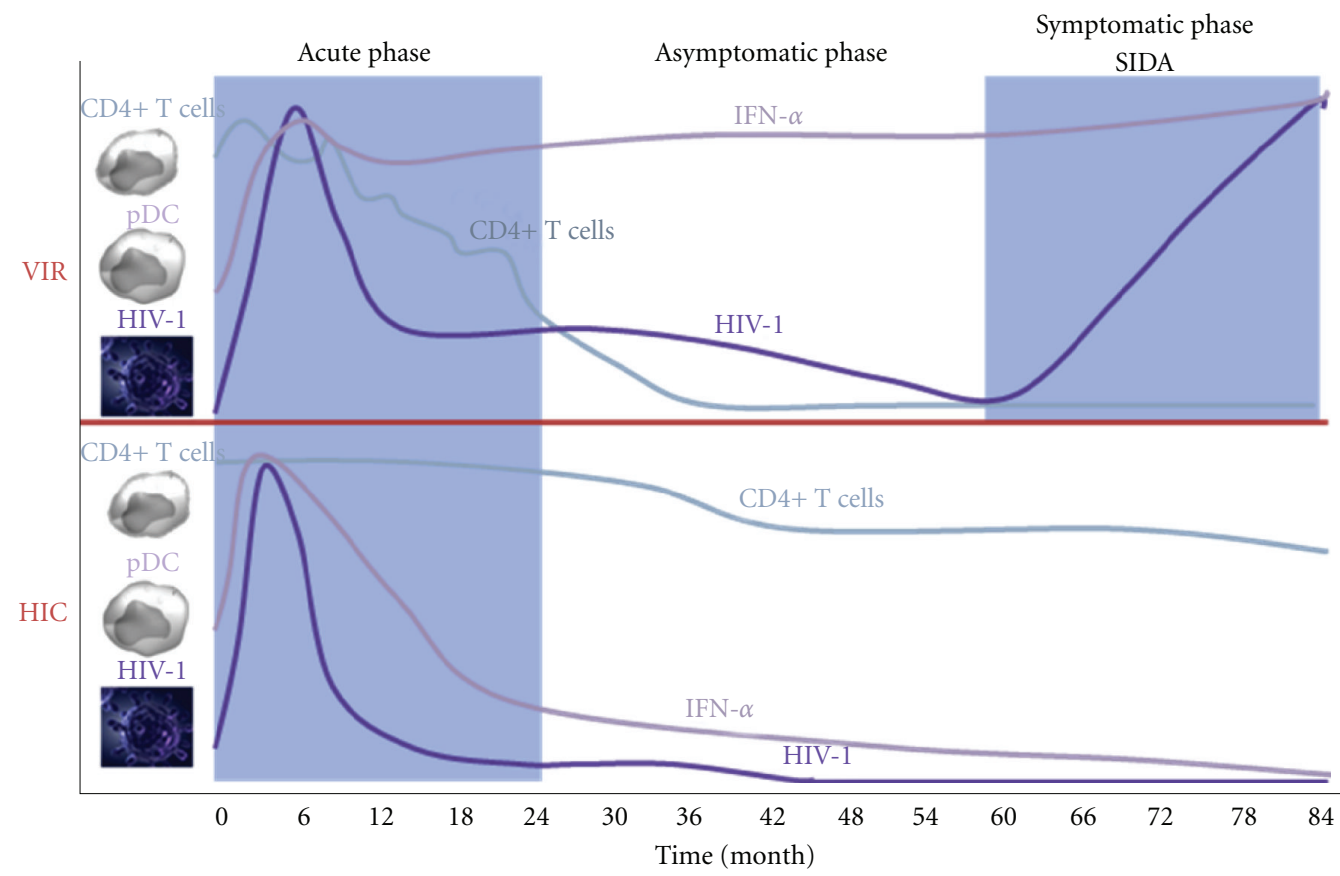

FIgURE 1: Comparison between HIV-1 viremic patients and HIV-1-Infected controllers during the different phases of infection. Viral load and lymphopenia controlled in HIV controllers versus viral load and lymphopenia uncontrolled in viremic. Decrease of IFN- $\alpha$ production versus no decrease of IFN- $\alpha$ production in viremic.

TABLE 1: Characteristic of HIV controllers and viremic patients.

\begin{tabular}{|c|c|c|c|c|c|c|}
\hline Group & Age & $\begin{array}{c}\text { Viral load } \\
\text { (copies } / \mathrm{mL} \text { ) }\end{array}$ & $\begin{array}{l}\text { CD4+ count } \\
\text { (cells/mL) }\end{array}$ & $\begin{array}{c}\text { Blood pDC } \\
\text { number }\end{array}$ & $\begin{array}{c}\text { IFN- } \alpha \\
\text { production }\end{array}$ & $\begin{array}{l}\text { In vivo } \\
\text { TRAIL }\end{array}$ \\
\hline Controllers $(n=22)$ & 45 & $<50$ & 718 & No decrease & ++++ & No \\
\hline Viremic $(N=18)$ & 42 & 26700 & 612 & Decrease & + & Yes \\
\hline
\end{tabular}

compared to CD4+ T cells from HAART patients and from healthy donors.

The hallmark of HIV infection is CD4+ T-cell depletion. This lymphopenia is due to several combined effects: destruction of HIV-infected cells, increased cell death of uninfected CD4+ T cells, and impair renewal [70]. Functional memory $\mathrm{T}$ cells have a long-lasting protection after exposure to pathogens $[71,72]$. Preservation of the central memory $\left(\mathrm{T}_{\mathrm{CM}}\right) \mathrm{CD} 4+\mathrm{T}$-cell compartment observed in HIV controllers was better than in untreated HIV progressors and individuals under therapy [73]. We also noticed a higher expression of the IL-7 receptor and CCR7, which suggests differences in $\mathrm{T}_{\mathrm{CM}}$ of HIV controllers homing patterns [73].

Physiological signals, in particular to immunomodulatory cytokines, decrease during chronic immune phase of HIV infection. One of the first signs of the immune deficiency that precedes CD4+ lymphopenia in HIV-infected patients is the reduction of IL-2 production and the lack of response to this cytokine [74-77]. Furthermore, it has been shown that progressive HIV disease is associated with a decrease in responsiveness to IL-7 $[78,79]$, a cytokine that is crucial to the central production of CD4+ lymphocytes and to their peripheral homeostasis (reviewed in [80]). The T-cell access to IL-7 on the fibroblastic reticular cell network is restricted by collagen deposition in lymphoid tissue, resulting in apoptosis and depletion of T cells [81]. Two clinical trials using IL-7 administration in ART-treated patients gave promising results in terms of reconstitution of CD4+ T-cell subsets $[82,83]$. IL-7 treatment may also help to purge viral reservoirs [80].

HIV-specific CD4+ T cells from HIV controllers divide more rapidly than those from viremic patients or ART patients [84]. HIV-specific CD4+ T cells in HIV controllers have the capacity to respond to minimal amounts of antigens. This may contribute to the better response of HIVspecific CD4+ T cell observed in controllers compared to ART-treated subjects. It remains to be determined whether or not HIV-specific CD4+ T cells can also have significant antiviral effects in vivo.

During acute HIV infection, massive destruction of the memory CD4+ T-cell compartment mostly occurs in lymphoid tissues, in particular in the gut-associated lymphoid tissue (GALT) [67, 85, 86]. All these events are mainly responsible for HIV immunopathogenesis. We noticed that the level of T-cell activation is lower in HIV controllers than in untreated viremic subjects, but higher than observed in healthy donors and individuals on successful ART [87]. Indeed, data indicate the presence of bacterial translocation 
in HIV controllers [87], in contrast to healthy donors. This indicates that HIV controllers have a successful viral control and they present lower detrimental consequences of chronic immune activation, including CD4+ T-cell loss [87].

In conclusion, $\mathrm{HIV}$-specific $\mathrm{CD} 4+\mathrm{T}$ cells are associations of some HLA Class II alleles with lower viral loads showed in some reports, which has so far not been confirmed in GWAS studies of HIV controllers. CD4+ T cells from HIV controllers are also more robust and polyfunctional in terms of cytokine secretion. They maintain high responses in spite of low antigen load, in contrast to ART-treated subjects in whom HIV-specific CD4+ T cells decrease on therapy. There is a higher growth kinetics and functional avidity of HIV-specific CD4+ T cells of HIV controllers. Interestingly, we noticed a lower expression of CTLA-4, an important inhibitory molecule, on HIV-specific CD4+ T cells of elite controllers.

\section{Hypothetic Model for HIV Controllers}

Recent findings concerning HIV controllers argue in favor of a strong pDC response during acute infection and a significantly more robust, polyfunctional HIV-specific CD4+ T cells.

The first response against HIV infection involves IFN- $\alpha$ production by most of immune cells including $\mathrm{pDC}$. The fact that IFN- $\alpha$ production was higher in HIV controllers than in viremic patients suggests that the control of HIV replication could be better (Figure 1) [40]. In addition to this efficient viral control, HIV-specific CD4+ T-cell response was shown to have a higher magnitude. HIV-specific CD4+ $\mathrm{T}$ cells from HIV controllers divide more rapidly than comparable lines from viremic patients. This study also identified a subpopulation of HIV-specific CD4+ T cells in HIV controllers endowed with a higher functional avidity compared to noncontrollers.

Considering these experimental data, we can hypothesize that innate immune response during acute phase is central and will determine the controller phenotype. Increased IFN$\alpha$ production and better CD4+ T-cell response will lead to an efficient viral control. In our hypothetic model, the number of viruses is crucial. We demonstrated that the apoptotic marker TRAIL, which is regulated by type I IFN, was positively correlated to viral load. Because TRAIL is probably one of the molecules responsible for T-cell depletion, the less the TRAIL is produced the less the disease progression is important. Similarly, during chronic phase, a reduced number of HIV particles induce less IFN$\alpha$ production, less proinflammatory cytokines. Thus, the chronic immune activation, which is probably one the most important processes leading to lymphopenia, is reduced in HIV controllers.

\section{Abbreviations}

$($ IFN- $\alpha)$ : Interferon alpha

(TLR): Toll-like receptor

(pDC): Plasmacytoid dendritic cell
(TRAIL): TNF-related apoptosis-inducing ligand

(IKpDC): TRAIL-expressing interferon-producing killer $\mathrm{pDC}$

(DR5): Death Receptor 5

HIV-1: Human immunodeficiency virus type 1.

\section{References}

[1] B. Schmidt, B. M. Ashlock, H. Foster, S. H. Fujimura, and J. A. Levy, "HIV-infected cells are major inducers of plasmacytoid dendritic cell interferon production, maturation, and migration," Virology, vol. 343, no. 2, pp. 256-266, 2005.

[2] F. P. Siegal, N. Kadowaki, M. Shodell et al., "The nature of the principal Type 1 interferon-producing cells in human blood," Science, vol. 284, no. 5421, pp. 1835-1837, 1999.

[3] G. Grouard, M. C. Rissoan, L. Filgueira, I. Durand, J. Banchereau, and Y. J. Liu, "The enigmatic plasmacytoid T cells develop into dendritic cells with interleukin (IL)-3 and CD40ligand," Journal of Experimental Medicine, vol. 185, no. 6, pp. 1101-1111, 1997.

[4] W. Barchet, M. Cella, and M. Colonna, "Plasmacytoid dendritic cells_-virus experts of innate immunity," Seminars in Immunology, vol. 17, no. 4, pp. 253-261, 2005.

[5] M. Colonna, G. Trinchieri, and Y. J. Liu, "Plasmacytoid dendritic cells in immunity," Nature Immunology, vol. 5, no. 12, pp. 1219-1226, 2004

[6] Y. J. Liu, "IPC: professional type 1 interferon-producing cells and plasmacytoid dendritic cell precursors," Annual Review of Immunology, vol. 23, pp. 275-306, 2005.

[7] M. Cella, D. Jarrossay, F. Faccheth et al., "Plasmacytoid monocytes migrate to inflamed lymph nodes and produce large amounts of type I interferon," Nature Medicine, vol. 5, no. 8, pp. 919-923, 1999.

[8] N. Kadowaki, S. Antonenko, J. Y. N. Lau, and Y. J. Liu, "Natural interferon $\alpha / \beta$-producing cells link innate and adaptive immunity," Journal of Experimental Medicine, vol. 192, no. 2, pp. 219-226, 2000.

[9] S. J. Gibson, J. M. Lindh, T. R. Riter et al., "Plasmacytoid dendritic cells produce cytokines and mature in response to the TLR7 agonists, imiquimod and resiquimod," Cellular Immunology, vol. 218, no. 1-2, pp. 74-86, 2002.

[10] A. Krug, A. R. French, W. Barchet et al., "TLR9-dependent recognition of MCMV by IPC and DC generates coordinated cytokine responses that activate antiviral NK cell function," Immunity, vol. 21, no. 1, pp. 107-119, 2004.

[11] G. Jego, A. K. Palucka, J. P. Blanck, C. Chalouni, V. Pascual, and J. Banchereau, "Plasmacytoid dendritic cells induce plasma cell differentiation through type I interferon and interleukin 6," Immunity, vol. 19, no. 2, pp. 225-234, 2003.

[12] G. X. Yang, Z. X. Lian, K. Kikuchi et al., "Plasmacytoid dendritic cells of different origins have distinct characteristics and function: studies of lymphoid progenitors versus myeloid progenitors," The Journal of Immunology, vol. 175, no. 11, pp. 7281-7287, 2005.

[13] D. Jarrossay, G. Napolitani, M. Colonna, F. Sallusto, and A. Lanzavecchia, "Specialization and complementarity in microbial molecule recognition by human myeloid and plasmacytoid dendritic cells," European Journal of Immunology, vol. 31, no. 11, pp. 3388-3393, 2001.

[14] N. Kadowaki and Y. J. Liu, "Natural type I interferonproducing cells as a link between innate and adaptive immunity," Human Immunology, vol. 63, no. 12, pp. 1126-1132, 2002. 
[15] H. Hemmi, T. Kaisho, O. Takeuchi et al., "Small-antiviral compounds activate immune cells via the TLR7 MyD88dependent signaling pathway," Nature Immunology, vol. 3, no. 2, pp. 196-200, 2002.

[16] S. S. Diebold, T. Kaisho, H. Hemmi, S. Akira, and C. Reis E Sousa, "Innate antiviral responses by means of TLR7mediated recognition of single-stranded RNA," Science, vol. 303, no. 5663, pp. 1529-1531, 2004.

[17] F. Heil, H. Hemmi, H. Hochrein et al., "Species-specific recognition of single-stranded RNA via till-like receptor 7 and 8," Science, vol. 303, no. 5663, pp. 1526-1529, 2004.

[18] J. M. Lund, L. Alexopoulou, A. Sato et al., "Recognition of single-stranded RNA viruses by Toll-like receptor 7," Proceedings of the National Academy of Sciences of the United States of America, vol. 101, no. 15, pp. 5598-5603, 2004.

[19] H. Hemmi, O. Takeuchi, T. Kawai et al., "A Toll-like receptor recognizes bacterial DNA," Nature, vol. 408, no. 6813, pp. 740$745,2000$.

[20] J. Lund, A. Sato, S. Akira, R. Medzhitov, and A. Iwasaki, “Tolllike receptor 9-mediated recognition of Herpes simplex virus2 by plasmacytoid dendritic cells," Journal of Experimental Medicine, vol. 198, no. 3, pp. 513-520, 2003.

[21] O. Duramad, K. L. Fearon, B. Chang et al., "Inhibitors of TLR-9 act on multiple cell subsets in mouse and man in vitro and prevent death in vivo from systemic inflammation," The Journal of Immunology, vol. 174, no. 9, pp. 5193-5200, 2005.

[22] C. Guiducci, G. Ott, J. H. Chan et al., "Properties regulating the nature of the plasmacytoid dendritic cell response to Tolllike receptor 9 activation," Journal of Experimental Medicine, vol. 203, no. 8, pp. 1999-2008, 2006.

[23] K. Honda, Y. Ohba, H. Yanai et al., "Spatiotemporal regulation of MyD88-IRF-7 signalling for robust type-I interferon induction," Nature, vol. 434, no. 7036, pp. 1035-1040, 2005.

[24] K. Honda, H. Yanai, H. Negishi et al., "IRF-7 is the master regulator of type-I interferon-dependent immune responses," Nature, vol. 434, no. 7034, pp. 772-777, 2005.

[25] S. Uematsu, S. Sato, M. Yamamoto et al., "Interleukin1 receptor-associated kinase-1 plays an essential role for Toll-like receptor (TLR)7- and TLR9-mediated interferon- $\alpha$ induction," Journal of Experimental Medicine, vol. 201, no. 6, pp. 915-923, 2005.

[26] K. Hoshino, T. Sugiyama, M. Matsumoto et al., "I $\kappa$ B kinase$\alpha$ is critical for interferon- $\alpha$ production induced by Toll-like receptors 7 and 9," Nature, vol. 440, no. 7086, pp. 949-953, 2006.

[27] C. Guiducci, C. Ghirelli, M. A. Marloie-Provost et al., "PI3K is critical for the nuclear translocation of IRF-7 and type I IFN production by human plasmacytoid predendritic cells in response to TLR activation," Journal of Experimental Medicine, vol. 205, no. 2, pp. 315-322, 2008.

[28] A. Dzionek, Y. Inagaki, K. Okawa et al., "Plasmacytoid dendritic cells: from specific surface markers to specific cellular functions," Human Immunology, vol. 63, no. 12, pp. 1133-1148, 2002.

[29] A. Dzionek, Y. Sohma, J. Nagafune et al., "BDCA-2, a novel plasmacytoid dendritic cell-specific type II C-type lectin, mediates antigen capture and is a potent inhibitor of interferon $\alpha / \beta$ induction," Journal of Experimental Medicine, vol. 194, no. 12, pp. 1823-1834, 2001.

[30] R. Tordjman, Y. Lepelletier, V. Lemarchandel et al., "A neuronal receptor, neuropilin-I, is essential for the initiation of the primary immune response," Nature Immunology, vol. 3, no. 5, pp. 477-482, 2002.
[31] M. Salio, M. Cella, W. Vermi et al., "Plasmacytoid dendritic cells prime IFN- $\gamma$-secreting melanoma-specific CD8 lymphocytes and are found in primary melanoma lesions," European The Journal of Immunology, vol. 33, no. 4, pp. 1052-1062, 2003.

[32] F. O. Nestle, C. Conrad, A. Tun-Kyi et al., "Plasmacytoid predendritic cells initiate psoriasis through interferon- $\alpha$ production," Journal of Experimental Medicine, vol. 202, no. 1, pp. 135-143, 2005.

[33] C. Bangert, J. Friedl, G. Stary, G. Stingl, and T. Kopp, "Immunopathologic features of allergic contact dermatitis in humans: participation of plasmacytoid dendritic cells in the pathogenesis of the disease?" Journal of Investigative Dermatology, vol. 121, no. 6, pp. 1409-1418, 2003.

[34] M. Colonna, "Toll-like receptors and IFN- $\alpha$ : partners in autoimmunity," Journal of Clinical Investigation, vol. 116, no. 9, pp. 2319-2322, 2006.

[35] A. Marshak-Rothstein, "Toll-like receptors in systemic autoimmune disease," Nature Reviews Immunology, vol. 6, no. 11, pp. 823-835, 2006.

[36] V. Soumelis, L. Scott, F. Gheyas et al., "Depletion of circulating natural type 1 interferon-producing cells in HIV-infected AIDS patients," Blood, vol. 98, no. 4, pp. 906-912, 2001.

[37] I. Kamga, S. Kahi, L. Develioglu et al., "Type I interferon production is profoundly and transiently impaired in primary HIV-1 infection," Journal of Infectious Diseases, vol. 192, no. 2, pp. 303-310, 2005.

[38] M. Müller-Trutwin and A. Hosmalin, "Role for plasmacytoid dendritic cells in anti-HIV innate immunity," Immunology and Cell Biology, vol. 83, no. 5, pp. 578-585, 2005.

[39] L. Barblu, K. Machmach, C. Gras et al., "Plasmacytoid dendritic cells ( $p D C s$ ) from HIV controllers produce interferona and differentiate into functional killer pDCs under HIV activation," Of Infectious Diseases, vol. 206, no. 5, pp. 790-801, 2012.

[40] K. Machmach, M. Leal, C. Gras et al., "Plasmacytoid dendritic cells reduce HIV production in elite controllers," Journal of Virology, vol. 86, no. 8, pp. 4245-4252, 2012.

[41] P. Fitzgerald-Bocarsly and E. S. Jacobs, "Plasmacytoid dendritic cells in HIV infection: striking a delicate balance," Journal of Leukocyte Biology, vol. 87, no. 4, pp. 609-620, 2010.

[42] A. Benlahrech and S. Patterson, "HIV-1 infection and induction of interferon alpha in plasmacytoid dendritic cells," Current Opinion in HIV and AIDS, vol. 6, no. 5, pp. 373-378, 2011.

[43] K. N. Brown, V. Wijewardana, X. Liu, and S. M. BarrattBoyes, "Rapid influx and death of plasmacytoid dendritic cells in lymph nodes mediate depletion in acute simian immunodeficiency virus infection," PLoS Pathogens, vol. 5, no. 5, Article ID e1000413, 2009.

[44] L. Fong, M. Mengozzi, N. W. Abbey, B. G. Herndier, and E. G. Engleman, "Productive infection of plasmacytoid dendritic cells with human immunodeficiency virus type 1 is triggered by CD40 ligation," Journal of Virology, vol. 76, no. 21, pp. 11033-11041, 2002.

[45] H. Donaghy, B. Gazzard, F. Gotch, and S. Patterson, "Dysfunction and infection of freshly isolated blood myeloid and plasmacytoid dendritic cells in patients infected with HIV-1," Blood, vol. 101, no. 11, pp. 4505-4511, 2003.

[46] M. Otero, G. Nunnari, D. Leto et al., "Peripheral blood dendritic cells are not a major reservoir for HIV type 1 in infected individuals on virally suppressive HAART," AIDS Research and Human Retroviruses, vol. 19, no. 12, pp. 10971103, 2003. 
[47] N. Hansjee, G. R. Kaufmann, C. Strub, R. Weber, M. Battegay, and P. Erb, "Persistent apoptosis in HIV-1-infected individuals receiving potent antiretroviral therapy is associated with poor recovery of CD4+ T lymphocytes," Journal of Acquired Immune Deficiency Syndromes, vol. 36, no. 2, pp. 671-677, 2004.

[48] M. Lichtner, C. Marañón, P. O. Vidalain et al., "HIV type 1infected dendritic cells induce apoptotic death in infected and uninfected primary CD4+ T lymphocytes," AIDS Research and Human Retroviruses, vol. 20, no. 2, pp. 175-182, 2004.

[49] G. Stary, I. Klein, S. Kohlhofer et al., "Plasmacytoid dendritic cells express TRAIL and induce CD4+ T-cell apoptosis in HIV1 viremic patients," Blood, vol. 114, no. 18, pp. 3854-3863, 2009.

[50] C. Lehmann, M. Lafferty, A. Garzino-Demo et al., "Plasmacytoid dendritic cells accumulate and secrete interferon alpha in lymph nodes of HIV-1 patients," PloS ONE, vol. 5, no. 6, Article ID e11110, 2010.

[51] J. F. Fonteneau, M. Larsson, A. S. Beignon et al., "Human immunodeficiency virus type 1 activates plasmacytoid dendritic cells and concomitantly induces the bystander maturation of myeloid dendritic cells," Journal of Virology, vol. 78, no. 10, pp. 5223-5232, 2004.

[52] J. P. Herbeuval, J. Nilsson, A. Boasso et al., "Differential expression of IFN- $\alpha$ and TRAIL/DR5 in lymphoid tissue of progressor versus nonprogressor HIV-1-infected patients," Proceedings of the National Academy of Sciences of the United States of America, vol. 103, no. 18, pp. 7000-7005, 2006.

[53] A. S. Beignon, K. McKenna, M. Skoberne et al., "Endocytosis of HIV-1 activates plasmacytoid dendritic cells via Toll-like receptor-viral RNA interactions," Journal of Clinical Investigation, vol. 115, no. 11, pp. 3265-3275, 2005.

[54] L. Chaperot, A. Blum, O. Manches et al., "Virus or TLR agonists induce TRAIL-mediated cytotoxic activity of plasmacytoid dendritic cells," The Journal of Immunology, vol. 176, no. 1, pp. 248-255, 2006.

[55] A. W. Hardy, D. R. Graham, G. M. Shearer, and J. P. Herbeuval, "HIV turns plasmacytoid dendritic cells (pDC) into TRAILexpressing killer $\mathrm{pDC}$ and down-regulates HIV coreceptors by Toll-like receptor 7-induced IFN- $\alpha$, Proceedings of the National Academy of Sciences of the United States of America, vol. 104, no. 44, pp. 17453-17458, 2007.

[56] E. Khatissian, M. G. Tovey, M. C. Cumont et al., "The relationship between the interferon $\alpha$ response and viral burden in primary SIV infection," AIDS Research and Human Retroviruses, vol. 12, no. 13, pp. 1273-1278, 1996.

[57] B. Reizis, A. Bunin, H. S. Ghosh, K. L. Lewis, and V. Sisirak, "Plasmacytoid dendritic cells: recent progress and open questions," Annual Review of Immunology, vol. 29, pp. 163-183, 2011.

[58] B. Malleret, B. Manéglier, I. Karlsson et al., "Primary infection with simian immunodeficiency virus: plasmacytoid dendritic cell homing to lymph nodes, type I interferon, and immune suppression," Blood, vol. 112, no. 12, pp. 4598-4608, 2008.

[59] S. M. Barratt-Boyes, V. Wijewardana, and K. N. Brown, "In acute pathogenic SIV infection plasmacytoid dendritic cells are depleted from blood and lymph nodes despite mobilization," Journal of Medical Primatology, vol. 39, no. 4, pp. 235-242, 2010.

[60] A. Biancotto, J. C. Grivel, S. J. Iglehart et al., "Abnormal activation and cytokine spectra in lymph nodes of people chronically infected with HIV-1," Blood, vol. 109, no. 10, pp. 4272-4279, 2007.
[61] C. Cellerai, A. Harari, H. Stauss et al., "Early and prolonged antiretroviral therapy is associated with an HIV-1-specific Tcell profile comparable to that of long-term non-progressors," PLoS ONE, vol. 6, no. 4, Article ID e18164, 2011.

[62] J. N. Mandl, A. P. Barry, T. H. Vanderford et al., "Divergent TLR7 and TLR9 signaling and type I interferon production distinguish pathogenic and nonpathogenic AIDS virus infections," Nature Medicine, vol. 14, no. 10, pp. 1077-1087, 2008.

[63] O. M. Diop, M. J. Y. Ploquin, L. Mortara et al., "Plasmacytoid dendritic cell dynamics and alpha interferon production during simian immunodeficiency virus infection with a nonpathogenic outcome," Journal of Virology, vol. 82, no. 11, pp. 5145-5152, 2008.

[64] B. Jacquelin, V. Mayau, B. Targat et al., "Nonpathogenic SIV infection of African green monkeys induces a strong but rapidly controlled type I IFN response," Journal of Clinical Investigation, vol. 119, no. 12, pp. 3544-3555, 2009.

[65] S. E. Bosinger, Q. Li, S. N. Gordon et al., "Global genomic analysis reveals rapid control of a robust innate response in SIV-infected sooty mangabeys," Journal of Clinical Investigation, vol. 119, no. 12, pp. 3556-3572, 2009.

[66] V. Sivaraman, L. Zhang, and L. Su, "Type I interferon contributes to $\mathrm{CD} 4+\mathrm{T}$ cell depletion induced by infection with HIV-1 in the human thymus," Journal of Virology, vol. 85, no. 17, pp. 9243-9246, 2011.

[67] D. C. Douek, L. J. Picker, and R. A. Koup, "T cell dynamics in HIV-1 infection," Annual Review of Immunology, vol. 21, pp. 265-304, 2003.

[68] A. Okoye, M. Meier-Schellersheim, J. M. Brenchley et al., "Progressive CD4+ central-memory $\mathrm{T}$ cell decline results in CD4+ effector-memory insufficiency and overt disease in chronic SIV infection," Journal of Experimental Medicine, vol. 204, no. 9, pp. 2171-2185, 2007.

[69] J. van Grevenynghe, F. A. Procopio, Z. He et al., "Transcription factor FOXO3a controls the persistence of memory CD4+ T cells during HIV infection," Nature Medicine, vol. 14, no. 3, pp. 266-274, 2008.

[70] J. M. McCune, "The dynamics of CD4+ T-cell depletion in HIV disease," Nature, vol. 410, no. 6831, pp. 974-979, 2001.

[71] R. M. Troyer, J. McNevin, Y. Liu et al., "Variable fitness impact of HIV-1 escape mutations to cytotoxic T lymphocyte (CTL) response," PLoS Pathogens, vol. 5, no. 4, Article ID e1000365, 2009.

[72] L. Harrison, H. Castro, P. Cane et al., "The effect of transmitted HIV-1 drug resistance on pre-therapy viral load," AIDS, vol. 24, no. 12, pp. 1917-1922, 2010.

[73] S. J. Potter, C. Lacabaratz, O. Lambotte et al., "Preserved central memory and activated effector memory CD4+ Tcell subsets in human immunodeficiency virus controllers: an ANRS EP36 study," Journal of Virology, vol. 81, no. 24, pp. 13904-13915, 2007.

[74] M. Kryworuchko, V. Pasquier, and J. Thèze, "Human immunodeficiency virus-1 envelope glycoproteins and anti-CD4 antibodies inhibit interleukin-2-induced Jak/STAT signalling in human CD4+ T lymphocytes," Clinical and Experimental Immunology, vol. 131, no. 3, pp. 422-427, 2003.

[75] M. Kryworuchko, V. Pasquier, H. Keller et al., "Defective interleukin-2-dependent STAT5 signalling in CD8 T lymphocytes from HIV-positive patients: restoration by antiretroviral therapy," AIDS, vol. 18, no. 3, pp. 421-426, 2004.

[76] D. David, L. Bani, J. L. Moreau et al., "Regulatory dysfunction of the interleukin-2 receptor during HIV infection and the impact of triple combination therapy," Proceedings of 
the National Academy of Sciences of the United States of America, vol. 95, no. 19, pp. 11348-11353, 1998.

[77] D. David, L. Bani, J. L. Moreau et al., "Dysregulation of interleukin-2 receptor $\beta$ and interleukin-2 receptor $\gamma$ expression during HIV infection," European Cytokine Network, vol. 9, no. 3, pp. 97-101, 1998.

[78] M. Paiardini, B. Cervasi, H. Albrecht et al., "Loss of CD127 expression defines an expansion of effector CD8+ T cells in HIV-infected individuals," The Journal of Immunology, vol. 174, no. 5, pp. 2900-2909, 2005.

[79] R. M. Dunham, B. Cervasi, J. M. Brenchley et al., "CD127 and CD25 expression defines CD4+ T cell subsets that are differentially depleted during HIV infection," The Journal of Immunology, vol. 180, no. 8, pp. 5582-5592, 2008.

[80] A. Chahroudi and G. Silvestri, "Interleukin-7 in HIV pathogenesis and therapy," European Cytokine Network, vol. 21, no. 3, pp. 202-207, 2010.

[81] M. Zeng, A. J. Smith, S. W. Wietgrefe et al., "Cumulative mechanisms of lymphoid tissue fibrosis and T cell depletion in HIV-1 and SIV infections," Journal of Clinical Investigation, vol. 121, no. 3, pp. 998-1008, 2011.

[82] I. Sereti, R. M. Dunham, J. Spritzler et al., "IL-7 administration drives T cell-cycle entry and expansion in HIV-1 infection," Blood, vol. 113, no. 25, pp. 6304-6314, 2009.

[83] Y. Levy, C. Lacabaratz, L. Weiss et al., "Enhanced T cell recovery in HIV-1-infected adults through IL-7 treatment," Journal of Clinical Investigation, vol. 119, no. 4, pp. 997-1007, 2009.

[84] B. Vingert, S. Perez-Patrigeon, P. Jeannin et al., "HIV controller CD4+ $\mathrm{T}$ cells respond to minimal amounts of Gag antigen due to high TCR avidity," PLoS Pathogens, vol. 6, no. 2, Article ID e1000780, 2010.

[85] J. M. Brenchley, T. W. Schacker, L. E. Ruff et al., "CD4+ T cell depletion during all stages of HIV disease occurs predominantly in the gastrointestinal tract," Journal of Experimental Medicine, vol. 200, no. 6, pp. 749-759, 2004.

[86] J. J. Mattapallil, D. C. Douek, B. Hill, Y. Nishimura, M. Martin, and M. Roederer, "Massive infection and loss of memory CD4+ T cells in multiple tissues during acute SIV infection," Nature, vol. 434, no. 7037, pp. 1093-1097, 2005.

[87] P. W. Hunt, J. Brenchley, E. Sinclair et al., "Relationship between $\mathrm{T}$ cell activation and CD4+ $\mathrm{T}$ cell count in HIVseropositive individuals with undetectable plasma HIV RNA levels in the absence of therapy," Journal of Infectious Diseases, vol. 197, no. 1, pp. 126-133, 2008. 


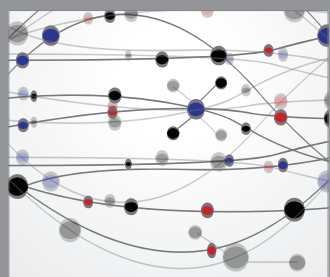

The Scientific World Journal
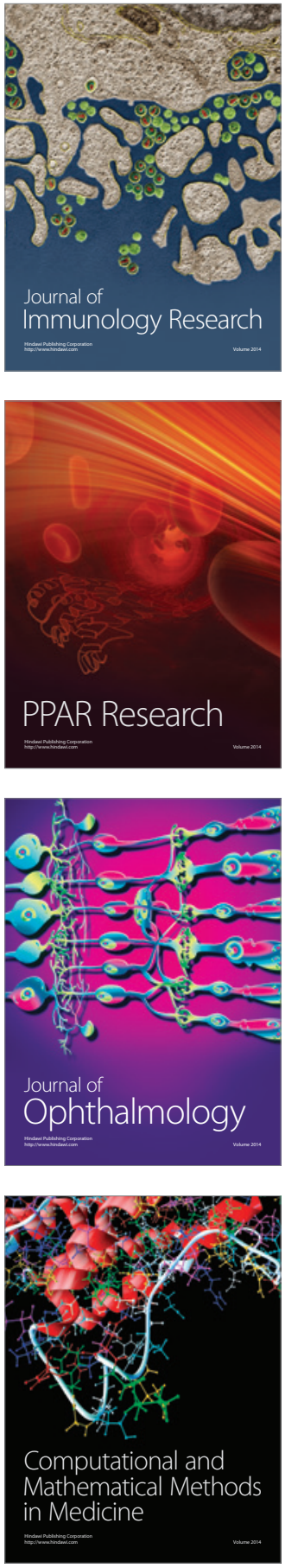

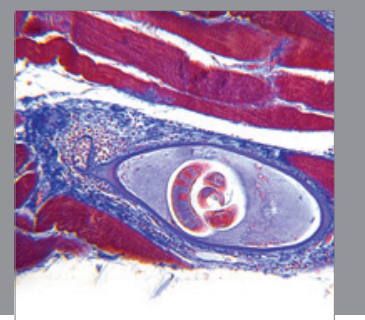

Gastroenterology

Research and Practice
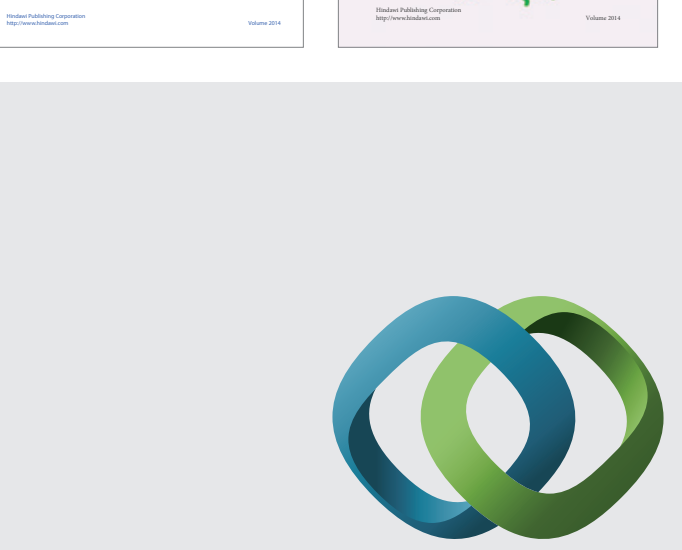

\section{Hindawi}

Submit your manuscripts at

http://www.hindawi.com
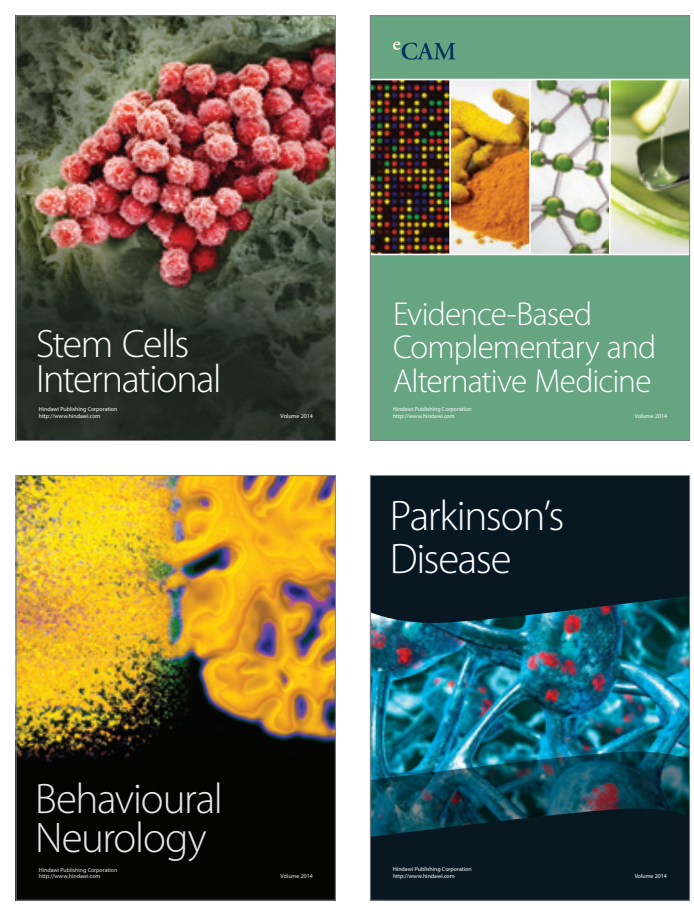

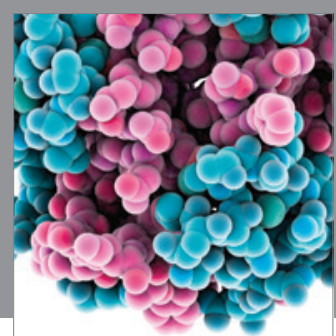

Journal of
Diabetes Research

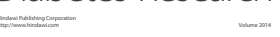

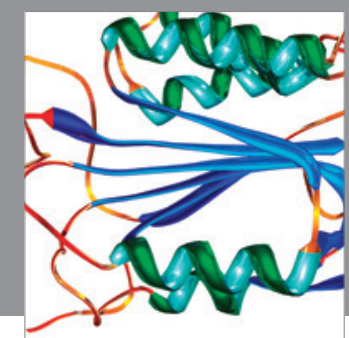

Disease Markers
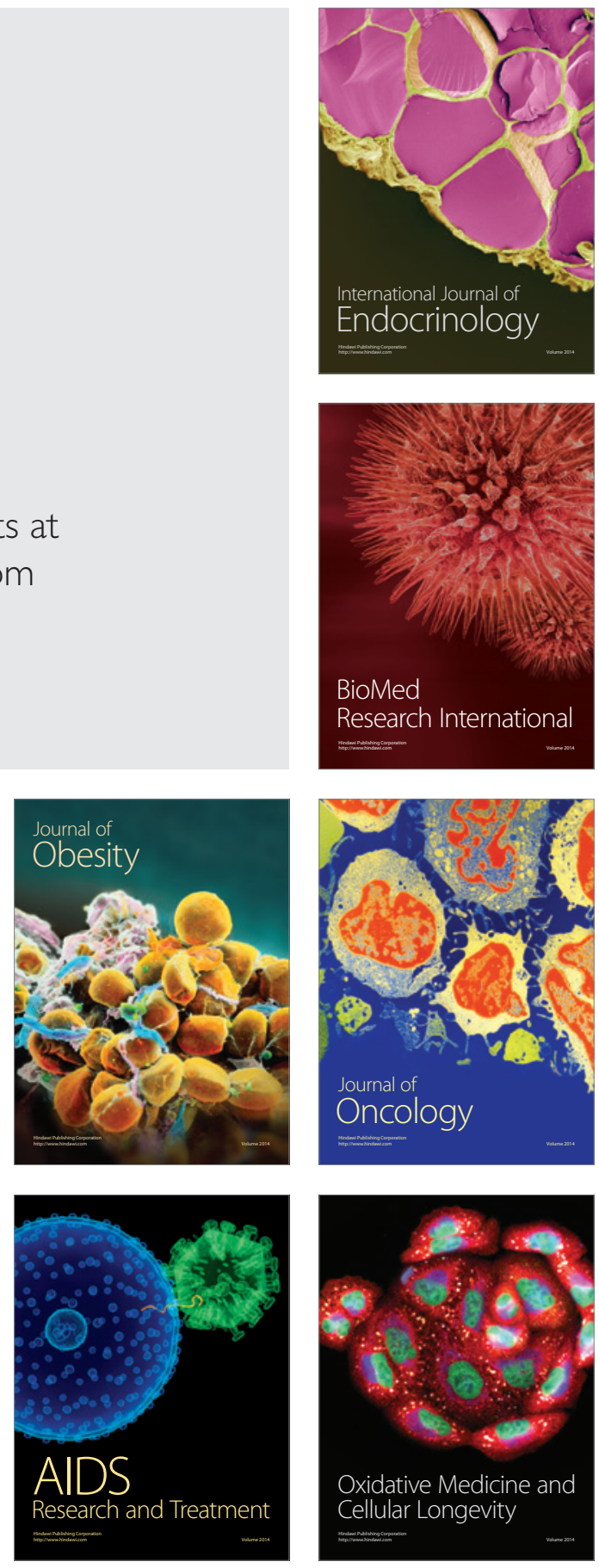